\title{
Transitar no habitar e habitar transitando: nos rastos da experiência criativa de um pintor abstrato residente no Pisão'
}

José Manuel Resende (https://orcid.org/0000-0002-7233-2237), Universidade de Évora, Évora, Portugal". José Maria Carvalho (https://orcid.org/0000-0002-1479-2155), Universidade de Évora, Évora, Portugal"'.
Recebido: 30.03 .21 Aprovado: 02.06.21
Resumo: Tendo por fito a atividade de pintura abstrata de um residente numa instituição de apoio social, ensaiamos uma leitura a partir de uma pesquisa etnográfica de pendor pragmático-fenomenológico em curso que enfatiza a centralidade dos efeitos de temporalização na coordenação da ação situada. A experiência criativa inerente ao curso da ação da pintura requer que os atores que nela se envolvem se sincronizem e orientem, pelo que nos propomos identificar e descrever a pluralidade de temporalidades que pautam a pintura, bem como a malha de operações corporais, gestuais, objetais e discursivas que as imbricam.

Palavras-chave: Temporalidade. Situação. Criação artística. Sociologia pragmatista. Pisão.

Flowing in dwelling and dwelling in flowing: tracking the creative experience of an abstract painter resident of Pisão

Abstract: Contemplating the abstract painting process of a resident in a social care institution, we propose a reading based on an ongoing ethnographic research with a pragmatic-phenomenological approach that emphasizes the centrality of the temporalization effects in the coordination of the situated action. The creative experience inherent in the course of the action of painting requires that the actors involved in it synchronize and orient themselves, so we propose to identify and describe the plurality of temporalities that guide the painting process, as well as the mesh of bodily, gestural, objectual and discursive operations that overlap them.

Keywords: Temporality. Situation. Artistic creation. Pragmatist sociology. Pisão.

\section{Pesquisa financiada por:

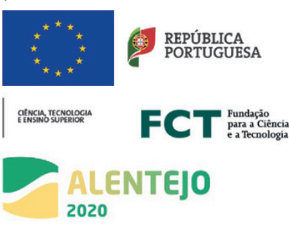

II. José Manuel Resende é professor catedrático de sociologia da Universidade de Évora, Évora, Portugal. <josemenator@ gmail.com>

III. José Maria Carvalho é doutorando em sociologia na Universidade de Évora,

Évora, Portugal. <carvalhoze10@ hotmail.com> 
1. A reflexão proposta no presente texto insere-se no trabalho de pesquisa que se tem vindo a desenvolver no âmbito de um projeto de doutoramento em sociologia, apostado em compreender a experiência criativa artística e as suas modalidades de (re) subjetivação junto de populações portadoras de vulnerabilidades várias em contexto institucional. 0 projeto ainda se encontra em curso, pelo que as leituras analíticas dispostas devem ter isso mesmo em conta, não podendo ser tomadas como resultados finais. Elas são, todavia, robustecidas por variadas outras entradas que, por economia de espaço, não puderam constar do texto e que são fruto de uma etnografia intensiva que leva cerca de cinco meses (já descontadas as interrupções devido à pandemia). No texto garantese $o$ anonimato dos participantes do estudo, nomeadamente pelo emprego de nomes fictícios. Nota ainda de agradecimento à Fundação para a Ciência e Tecnologia (FCT), entidade financiadora da pesquisa (referência de bolsa: 2020.07755.BD), ao Centro de Apoio Social do Pisão (Casp), instituição que acolhe a mesma

\section{A partir do Pisão: explorar as experiências criativas situadas dos seus residentes ${ }^{1}$}

$\mu$ atividade artística, nos seus mais variados ramos, é promovida em inúmeras instituições que trabalham junto de populações em contextos de vulnerabilidade e, em particular, com indivíduos portadores de patologia psiquiátrica. Se esta constatação se vê acompanhada pelo recente aumento de literatura científica em áreas do saber adstritas às mais diversas práticas clínicas e psicoterapêuticas, da arteterapia, em sentido estrito, à psicologia clínica, passando pelas ciências médicas, como a psiquiatria, até à própria arte, o mesmo não se verifica na sociologia. O nosso intuito, longe de se deter na averiguação dos motivos desta lacuna, é explorá-la, trazendo à liça uma série de questões que os fazeres artísticos colocam para aquele que se apresente com o objetivo de compreender a experiência criativa de um ponto de vista sociológico.

Para tanto, no âmbito de um projeto de doutoramento, temos vindo a levar a cabo uma pesquisa etnográfica que acompanha as atividades artísticas desenvolvidas no Centro de Apoio Social do Pisão (doravante, "Casp"), instituição situada no conceIho de Cascais (região metropolitana de Lisboa), pertencente ao Instituto da Segurança Social e gerida pela Santa Casa da Misericórdia. Com cerca de 350 residentes adultos/as em regime de internamento devido a patologia psiquiátrica (entre as quais predomina o quadro psicótico esquizofrénico) e/ou deficit cognitivo, o Casp acolhe, pois, uma população em situação de franca vulnerabilidade, em muitos casos agravada por dificuldades de cariz socioeconómico, requerendo apoios básicos de subsistência e de saúde. Além de visar assegurar as necessidades elementares de alimentação e higiene à sua população residente e de Ihe disponibilizar os cuidados clínicos e farmacológicos adequados, o Casp tem igualmente por objetivo zelar pelo seu equilíbrio bio-psico-social, favorecer os sentimentos de segurança, autoestima, autonomia e individualidade, assim como promover a sua reabilitação e reinserção na comunidade, quando possível. Uma das apostas do Casp com vista à prossecução destes desígnios é o desenvolvimento de ateliers de terapia ocupacional e artística. Debruçar-nos-emos sobre a prática da pintura, à qual se dedica, uma vez por semana, um grupo nunca superior a dez residentes, durante sensivelmente uma hora e meia a duas horas, e particularmente ao trabalho de um residente, Leopoldo, pintor abstrato.

Orientados no quadro das sociologias pragmatistas, propomo-nos estudar a experiência criativa artística. É nossa convicção que elas contêm aportes significativos, ao mesmo tempo que salvaguardar alguns dos inquestionáveis contributos da Teoria Ator-Rede (doravante, "ANT"), aprofundar outros tantos e até responder a algu- 
mas das suas insuficiências. Por isso mesmo, pese embora tratando-se aqui de um texto iminentemente analítico e arrimado em dados provenientes da pesquisa empírica, não nos inibiremos de, sempre que pertinente, lançar a discussão no quadro teórico das tradições que movem o presente dossier.

Declarar que se tem as situações concretas em que a ação se desenrola por unidade de análise tornou-se vulgar, muitas vezes ao preço de adotar irrefletidamente o conceito de situação. Neste texto, por isso, considerando que a ação é irremediavelmente situada, procuraremos elucidar a relação entre a (inter)ação e a situação. Se é verdade que uma das conquistas da ANT é precisamente a de superar em definitivo a aceção regional (Mol \& Law, 1994) da situação, demonstrando em inúmeros trabalhos que esta transcende um espaço-tempo recortado por determinações respetivamente euclidianas e cronológicas, alargando-a num espaço reticular e assim tornando frívola a discussão sociológica do par micro-macro e local-global em termos dualistas, não é menos verdade que ela não leva até às últimas consequências esta rutura, preservando uma determinação extensiva da situação.

Tal segue-se, a nosso ver, da sua abordagem deficitária à temporalidade, conforme já apontado por Theodore Schatzki (2010) ou Tim Ingold (2011). Como desejamos mostrar, a exploração das temporalidades na sua variedade e pluralidade composicional é uma via profícua para compreender as situações, na medida em que a ação nunca é uma unidade discreta, mas a própria transação com o meio ambiente, que inclui atividade e passividade, onde o organismo se faz sujeito pelo mesmo movimento em que o ambiente se torna meio potencial (da ação), um afetando e sendo afetado pelo outro (Dewey, 2008).

Se é uma sequência (Ogien, 2014), e não uma unidade, se ela está sempre em curso, não sendo delimitável a priori, então segue-se que a ação (i) contém inexoravelmente uma densidade temporal (Colapietro, 2013): é linha, não ponto, o que significa que se caracteriza essencialmente pelo seu "rasto" (no próprio agente, no outro e no meio ambiente), isto é, pela possibilidade do passado e do futuro, sem a qual a ação não seria mais do que a resposta a um estímulo. Além disso, sendo em primeiro lugar uma questão de transação, a ação (ii) é fundamentalmente situada. Fundamentalmente, pois que a situação não é propriamente um repositório externo da ação, mas sim um seu termo indissociável, já que é no mesmo processo em que o organismo deixa de responder a estímulos para agir que o meio ambiente passa a ser uma situação (Quéré \& Schoch, 1998). É na articulação destas duas linhas indissociáveis que a experiência se cose. A situação é o todo qualitativo (Dewey, 2008) que confere sentido à presença humana, que fornece apoios afetivos e cognitivos à ação, mas também uma atmosfera habitável onde simplesmente se e aos seus residentes e funcionários que nos acolheram com hospitalidade impar. 
pode estar. E é esta dimensão experiencial, segundo a qual a situação é um modo de durar intensivo e qualitativo, que faz dela um meio ecológico, mais do que uma rede (Ingold, 2000; 2011), de onde uma abordagem pragmático-fenomenológica.

A coordenação situada da ação passa, pois, inelutavelmente pela necessidade de ajustes temporais, residindo assim numa dimensão afetiva, rítmica, corporal, abaixo das convenções (Bidet, 2007; Brahy, 2014; Breviglieri, 2016). Nesta senda, recorreremos a algumas entradas do diário de campo (doravante, "DC") respeitantes a situações diretamente presenciadas pelo pesquisador em três sessões de pintura (22 de maio de 2020, 5 de junho de 2020 e 12 de junho de 2020) para identificar, descrever e compreender as diferentes temporalidades em jogo nas mesmas, bem como caracterizar as sequências de ação das quais elas provêm. Veremos que a temporalidade institucional que delimita a sessão de pintura é insuficiente para compreender a sua prática e experiência, sendo necessário seguir as linhas temporais que Ihes são imanentes e as modulam, rastreando a presença e as práticas dos vários participantes, objetos e discursos, todos eles geradores de efeitos de temporalização que tornam a situação criativa artística porosa e/ou imune a certas sequências de ação, que Ihe conferem linhas de continuidade e sedimentação, mas igualmente de fratura.

\section{Caso de estudo:}

\section{breve caracterização}

Salvo imponderáveis, o atelier de pintura do Casp decorre com uma frequência semanal, em dia, sala e horário predefinidos. As sessões são dinamizadas e supervisionadas por uma monitora, sempre a mesma, responsável pela atividade, secundada por mais um ou dois monitores, que podem variar. Em tese, participam os residentes que estejam formalmente inscritos na atividade, pese embora a monitora responsável nunca rejeite a presença daqueles que, não estando inscritos, pontualmente, mostrem o desejo de (experimentar) pintar, desde que a sala afetada tenha ainda espaço suficiente para os acolher. Tudo somado, a sessão raramente excede os dez participantes.

Nesta simples descrição procurámos, tanto quanto possível, salientar os traços institucionais gerais que delimitam a atividade em causa. Evidentemente, não seria despiciendo aprofundar a caracterização do local das atividades, os códigos deontológico e de conduta dos monitores, o nível de autonomia dos pintores ou os objetos e materiais que intervêm na atividade. Todavia, repare-se como não foi necessário abandonar o grau de generalidade descritiva adotado para perceber que é logo nele que se começa a revelar a sua insuficiência. Desde logo porque numa 
instituição com o volume e a densidade populacional aludidos (ao que acresce cerca de 150 funcionários) os imponderáveis referidos, sem beliscar a sua imponderabilidade, fazem parte do dia a dia, obrigando, não raras vazes, a alterar o local da sessão e até as próprias atividades levadas a cabo (se bem que sempre ligadas ao ramo da pintura); também porque, como se viu, o grupo de participantes, com exceção de um núcleo de cinco ou seis residentes, varia, assim como os monitores auxiliares. A incerteza e ambiguidade que as determinações institucionais visam apaziguar são inerentes à situação, pelo que é nossa conviç̧ão que a descrição que a mesma exige tem que ir para lá da identificação e caracterização do local, horário e participantes (humanos e não humanos). Estes formatos, mais ou menos cristalizados e, nessa medida, participando efetivamente na ordenação da situação, não são negligenciáveis, porém, somente adquirem sentido (logo, função e eficácia) quando reenviados para as situações em que os atores, face a problemas e anseios concretos, coordenam o curso da ação e modalizam o seu envolvimento na mesma.

\section{Leopoldo no ambiente do atelier:}

os usos dos saberes situados e a composição do seu curso

Partindo da seguinte entrada do DC, procuremos deslindar, tendo a dimensão temporal da (situ)ação como leitmotiv, a sua natureza composicional e plural, para que destarte possamos acompanhar a experiência criativa artística, no caso pictórica, mais do que já constituída e qualificada, no fazer-se que the é próprio, isto é, no seu ter lugar:

Um dos residentes recém-chegados à sessão, Leopoldo, dirige-se ao seu lugar, onde os seus materiais de trabalho (paleta, caixa com os tubos de tinta, tela, pincéis) se encontram organizados especificamente para si. Mal se senta, com a tela em branco à sua frente, questiona a monitora se é ele que coloca as tintas na paleta. Neste processo, acabo por intervir, perguntando-Ihe se vai iniciar uma tela nova. Ele responde-me que sim. Acrescenta ainda que, na sua pintura, "não parte de nenhuma imagem", que se trata de "pintura abstrata", que "demora cerca de duas a três horas a terminar" cada tela e que já expôs os seus trabalhos, alguns dos quais, inclusive, foram vendidos (DC, 22 Maio 2020).

Antes de mais, cabe-nos informar que as três sessões aqui evocadas através das anotações diarísticas decorreram num espaço partilhado com outras atividades ocupacionais de cariz mais oficinal ou ocupacional. A sala deve, assim, ser questionada e relativizada quanto à sua capacidade heurística: ela mostra-se, enquanto unidade, insuficiente para circunscrever espacialmente a atividade pictórica, reve- 
lando-se no seu lugar uma topografia afetiva-cognitiva complexa e mista (Breviglieri, 2012), denotada, de resto, na distribuição espacial dos residentes. É notório que os pintores se localizam a um canto da sala, reunidos em torno de duas mesas que ocupam talvez cerca de um quarto da sua dimensão total, as quais se encontram previamente arranjadas e equipadas pela monitora responsável em função de cada um dos residentes participantes e do respetivo grau de autonomia. Se os monitores circulam ao longo de toda a sala, os residentes raramente saem dos lugares afetados aos seus trabalhos, a não ser para a habitual interrupção a meio da sessão ou para ir à casa de banho. Tanto assim é que Leopoldo sabe imediatamente para onde se deve dirigir, reconhecendo, logo à entrada, o local onde o seu trabalho decorrerá, seja pela presença dos seus colegas de atividade no local apropriado, seja pelos materiais depositados em cima da mesa. Chegado à sala, Leopoldo detém um saber tácito e prático que o faz perceber a sala, não como um todo indiferenciado ou uniforme, mas como uma paisagem dotada de certas preensões e referências que ancoram as atividades (Chateauraynaud, 2017; Gibson, 1986; Ingold, 2000), matizando a sala, tornando-a passível de orientação.

Segue-se que devemos, em primeiro lugar, evitar subsumir esta diversidade de espacialidades e temporalidades numa unidade empírica que rasuraria as suas diferenças, assim obnubilando o acesso às particularidades da experiência pictórica. Contrariamente, rastreamos os traços de significância (no seu duplo sentido de significado e valor) tatuadores de relevos que demarcam regiões atmosféricas distintas numa mesma sala, mas que longe de serem incomunicáveis, se descobrem ao mesmo tempo ligadas por canais de passagem, mas na verdade frequentemente colocados à prova. É neste quadro que a multiplicidade de efeitos de temporalização e o modo como uns e outros se costuram na prática, abrindo assim a situação a distintos modos de durar, são o fito da presente análise.

Sem embargo da aparente facilidade e automatismo com que Leopoldo se dirigiu para a mesa da pintura, rapidamente nos apercebemos que não devemos incorrer no engodo de tratar aquilo que denominámos atmosferas, para enfatizar o seu caráter poroso e afetivo (Bidet, 2007), como espaços de determinação de disposições para agir. Aliás, talvez se nos imponha um parêntesis para efeitos de clarificação terminológica: aquilo que estamos a designar por atmosfera talvez seja, na verdade, apenas outro termo para epitetar o todo qualitativo que é a situação; não podemos sabê-lo com segurança, visto ser esta, justamente, aquilo que perseguimos. Talvez venhamos a ver na situação um movimento de ordenação mise en abyme da ação, o substrato, precisamente, da sua serialidade, sempre se (re)fazendo. Em todo o caso, o que podemos adiantar por ora é que toda a situação comporta um certo tónus afetivo que, por ter uma qualidade perfeitamente individualizada (embora 
não sendo nem subjetiva, nem objetiva), mas cujo aparecimento fenomenológico é difuso e vago, chamamos atmosfera (Gil, 2001).

Ora, a facilidade em reconhecer a sua região da sala e de para ela se encaminhar corresponde a uma temporalidade serena, fluída porque isenta de perturbações, onde o espaço e aquilo que o povoa prolonga o corpo que nele se move, fornecendo um conjunto de apoios - práticos e cognitivos - que reasseguram Leopoldo (Breviglieri, 2012; Thévenot, 2001). Mas a dúvida logo se insinua, interpondo-se sob a forma de interpelação verbal: quem é o responsável por colocar as tintas na paleta? E com ela uma outra temporalidade. Leopoldo, por momentos, ignora o passo seguinte e, por conseguinte, a adequabilidade da conduta a assumir torna-se problemática: deve ele tomar a iniciativa ou deve aguardar pela monitora? Esta dúvida atrela a incerteza, a tensão, por mais ligeiras que sejam.

\section{...na passagem dos tempos situados - buscas futuras titubeantes}

Como se passou de uma temporalidade a outra e qual a natureza dessa passagem? Devemos, segundo pensamos, afastar a hipótese de uma simples substituição. Por um lado, a temporalidade não se presta à análise, stricto sensu, ou seja, à operação que decompõe a organicidade e sequencialidade da ação em componentes ontologicamente distintas para depois, juntando-as mecanicamente, recompor a unidade (Dewey, 2008; Mead, 2010). Por outro lado, do ponto de vista empírico, o simples facto de Leopoldo (se auto-)interrogar vincula-o à situação, não só porque a própria dúvida só surge sob o fundo de um quadro de inteligibilidade minimamente estabilizado (Thévenot, 2019), estando sempre, desde o seu surgimento, já investida por este, mas também porque a pergunta, na medida em que é verbalmente formulada, solicita uma resposta, seja ela qual for, isto é, a reposição de uma temporalidade serena.

Então, somos tentados a ver nesta passagem, não tanto a troca de uma temporalidade por outra, quanto uma bifurcação onde o novo caminho traçado arrasta o anterior como seu avesso. Uma e outra acham-se enlaçadas, girando sobre si mesmas conforme a solidez dos traços de significância e as circunstâncias. É o que Laurent Thévenot (2019), do nosso ponto de vista acertadamente, indica a respeito da noção de engajamento: este não existe sem a promessa que abre um futuro em função do qual a ação se coordena e orienta. Deixar-se cair para o futuro, sem o que não se age, requer um mínimo de segurança, providenciada por processos de investimento em formas (Thévenot, 1984), os quais, ao mesmo tempo que sedimentam e facilitam o curso da ação, inevitavelmente sacrificam outras possibi- 
lidades de formatar. Assim, à fluidez e previsibilidade de um espaço confortável junta-se, como seu avesso insinuante e sempre à espreita, a dúvida, a incerteza, a outra possibilidade, e vice-versa.

Se esperamos ter esclarecido a relação entre as duas temporalidades, mostrando que a situação, conforme a entendemos, longe de ser um bloco monolítico, é iminentemente temporal, na medida em que dura, e durar é mudar, sabemos, contudo, que ficou por descrever esse momento-limite em que uma temporalidade se vê abalada por uma outra que a toma e desvia. Esse momento, na ocasião a que nos reportamos, parece-nos ser aquele em que Leopoldo e a tela-em-branco se encontram. Por encontro não nos referimos à mera presença da tela em branco no campo visual-percetivo de Leopoldo, mas ao momento em que aquela é o objeto intencionado deste. Como se sabe e se verá adiante, os objetos temporalizam (Law, 2002) por vias materiais e simbólicas.

O caso da tela-em-branco é especialmente curioso. É que como o seu conteúdo é a sua forma (superfície lisa, quadrangular ou retangular, branca), um identificando-se irremediavelmente com o outro, tem-se que ao mesmo tempo que a tela-em-branco nada diz (é a-significante) fala enquanto apelo ao fazer (a uma determinação externa que a venha completar e conferir sentido). Ela é, nesta aceção, o mais recalcitrante dos objetos, fixando Leopoldo a um presente insuperável (que só a irrupção do signo, em toda a amplitude que Charles S. Peirce (1998) Ihe confere, desbloquearia), e simultaneamente o mais simbólico, na medida em que, não detendo margens de significação definidas, clama não tanto por este ou aquele símbolo específico quanto pelo ato de inscrição em si, fundamento da simbolização. Não deixa de ser sintomático que Leopoldo nos diga, ainda nessa mesma sessão, que "não pensa em nada à partida", ou que utilize o verbo sair para explicar como lhe surgem os traços que ele depõe na tela ("os riscos saem-me naturalmente da cabeça" (DC, 22 Maio 2020). Neste apelo, Leopoldo não pode deixar de ser arrancado ao presente para se lançar no futuro - de onde, a irrupção da formulação verbal da pergunta, da possibilidade do diálogo, demandando projetar-se; de onde, a centralidade da "imaginação" no seu ato de pintar, e não tanto da "imitação", como também ainda nessa sessão nos declara. Já nos encontramos em condições, portanto, de identificar uma peculiaridade da experiência criativa em questão: a tela-em-branco gera um choque que tensiona a passagem do chegar ao permanecer na situação, o que significa que, contrariamente à larga maioria das experiências quotidianas, é no e pelo estado de incerteza e inquietude que Leopoldo nela se instala.

A este acresce um outro dado considerável. Quando Leopoldo nos refere que já expôs e vendeu telas, fá-lo num tom orgulhoso e brioso que aponta para a im- 
portância na experiência criativa da abertura de um horizonte de reconhecimento público. Repare-se:

Enquanto Leopoldo pinta, entra na sala uma funcionária do Casp que, caminhando até junto da monitora que acompanhava as atividades, entabula conversa com esta. A conversa desenrola-se sensivelmente a um metro de Leopoldo. Este mantém o foco no trabalho que por ora o prende, mas dá-se conta, com um breve e rápido olhar, da sua presença. A certa altura essa mesma funcionária recém-chegada dirige-se diretamente a Leopoldo, saudando-o e perguntando-Ihe se está tudo bem. Leopoldo interrompe o trabalho, sorridente, retribuindo a saudação. Quando perguntado se o trabalho corre bem, responde que sim, apontando com a mão, ato contínuo, para uma tela que se encontra atrás dele, encostada à parede, e completando que "essa também é minha". Após congratulá-lo pelo trabalho, a funcionária despede-se, circulando por outras paragens da sala. Leopoldo, por seu turno, volta ao seu trabalho, concentrado (DC, 12 Jun. 2020).

...atravessamentos temporais em atmosferas situadas:

atividades em ritmos plurais

Três linhas de reflexão já mencionadas encontram suporte na anotação supra: a pluralidade, encontro e porosidade de atmosferas diferentes no seio da mesma sala; o efeito de temporalização dos objetos; e, finalmente, o horizonte de reconhecimento implicado na experiência criativa.

Leopoldo encontra-se a pintar. Parece-nos interessante partir das circunstâncias que o levam a abandonar o foco atencional que até então concentrava na sua atividade para pensar a sua natureza. Noutros termos, tomar a perda de atenção como entrada para a atenção, o que pressupõe, assuma-se já, uma conceção de atividade polirrítmica. A atividade desdobra-se na medida em que o seu foco oscila, no que concerne aos conteúdos focados (intencionalidade), tanto quanto ao grau e qualidade do próprio foco (intensidade). A monitora e a funcionária conversam junto a ele. Apesar da proximidade física, ultrapassada, antes de tudo mais, pelo som ecoado no aparelho auditivo de Leopoldo pelas palavras proferidas por aquelas, não se pode dizer que as duas linhas de atividade (a conversa, de um lado, a pintura, de outro) propriamente se cruzem. Leopoldo, segundo nos é dado a perceber, dá pela presença da nova companhia. O facto, porém, é que uma sequência de atividade está para a outra como a água está para o azeite: coexistem sem se misturar. Qual o limite a partir do qual Leopoldo direciona realmente a atenção para elas? A interpelação direta, pessoal e intransmissível, sob a forma de saudação. A civilidade impõe-se ao alheamento que até então vigorava. Ou melhor, visto Leopoldo já ter 
dado conta da presença das duas senhoras e não ter intervindo, tudo indica, por considerar que era uma conversa que não Ihe dizia respeito, a civilidade já estava, desde o início, a investir a coexistência pacífica das duas séries de atividade sob a forma de desatenção civil (Goffman, 2011). Estas duas séries ligam-se, num primeiro momento, por laços de um respeito mútuo, se bem que desinteressado, maneira pela qual se assente e atesta a presença do outro como estando presente na mesma sala, mas sem a ela se vincular. Não se trata, é claro, de um total e completo desinteresse, sem o que, em rigor, a perceção não ocorreria; simplesmente, parece-nos que aqui o desinteresse é um modo de perceber pelo qual a sequência de atividade da monitora e da funcionária, por um lado, e a de Leopoldo, por outra, não se misturam, mas tocam-se tangencialmente, por força de um olhar de través que cuida em não demorar-se demasiadamente, rapidamente deslizando para outras paragens, justo modo através do qual ambas mantêm o seu curso diferenciado (Breviglieri \& Stavo-Debauge, 2007).

Cedo a conversa irrompe, pondo em jogo os termos convencionais da saudação cordial. As temporalidades das duas sequências da ação, até aqui inequivocamente separadas, mais do que subitamente interrompidas, cuja violência do inesperado não poderia deixar de produzir manifestações de sobressalto, invasão ou espanto, antes coagulam, expressão que mais não alude senão à maneira pela qual o curso de cada uma das sequências, se se interrompe, não cai no vazio, mas solidifica-se, prende-se, para que possa expandir-se até à outra sequência e acolhê-la. Neste processo, escusado é dizer, ambas as sequências, e respetivas temporalidades, se alteram: a conversa ajusta-se ao trabalho de Leopoldo, e o inverso. Não surpreende, por isso, que às saudações comuns se siga com naturalidade a pergunta dirigida pela funcionária a Leopoldo acerca do seu trabalho.

As duas sequências enlaçam-se, a situação transforma-se, e mais importante do que saber se ainda se trata, para Leopoldo, da mesma situação, sobrestimando e impondo divisas provavelmente artificiais ao fluxo da ação, é ser sensível a essa membrana, que no fundo é a própria situação (Goffman, 1961), que constantemente cortando e recortando o quadro pertinente da ação, bem como as suas vias possíveis, seleciona e reúne elementos das sequências anteriores e exclui outros. Se nos debruçarmos na conversa, vemos que ela toma como seu objeto o trabalho de Leopoldo. A resposta de Leopoldo fornecer-nos-á pistas significativas quanto ao modo como a sua pintura pode ser integrada na sequência dialógica.

Quando afiançou que não tem uma ideia do que vai pintar antes de iniciar o trabalho, impressão corroborada em outras conversas com o pesquisador onde em nenhum momento Leopoldo intenta determinar racionalmente a sua pintura, ele 
já legitimara a nossa suspeita de que a sua pintura dificilmente acede à ordem discursiva, ou melhor, que ela somente lhe acede transformando-se. No curto diálogo captado na anotação diarística supra essa impressão parece confirmar-se na resposta lacónica que devolve à pergunta da funcionária: questionado se o trabalho vai bem, um "sim" singelo, desacompanhado, sem o complemento necessário ao prosseguimento do diálogo acerca do trabalho. A resposta, sem deixar de corresponder à pergunta, seca-a na fonte, esconjurando o seu desenvolvimento.

O diálogo, apesar de tudo, não morre. O que acontece é que ele sofre uma ligeira torção que o desvia por forma a acomodar a pintura de Leopoldo. Como? Fazendo seguir ao "sim" um gesto que aponta para o local em que jaz a sua última tela terminada, identificando-a depois verbalmente como também sendo dele, Leopoldo opera com subtileza, independentemente de o saber, uma guinada no curso da interação. É que com o assinalado "também" confere sentido e ordem às duas telas. Ordem, do ponto de vista percetivo, pois implica que tenha havido um primeiro olhar para a tela atual que antecede o olhar para a segunda tela, mais antiga. Não única e exclusivamente devido ao "também", bem-entendido, mas sobretudo à sua integração sincrónica num conjunto de movimentos corporais e oculares que estruturam micro-sequências percetivas: primeiro, o corpo destapa a tela, desviando-se ligeiramente, posicionando-se de lado para a tela, fixando nela as atenções; depois, num breve lapso de tempo, indicando com a mão a outra tela, conduzindo os olhares da monitora e da funcionária a percorrer de um ponto ao outro, assim distendendo o tempo. Sentido, porque reúne ambas as telas ao longo de um mesmo traço comum á luz do qual adquirem inteligibilidade, o de serem pintadas por ele. Ordenando, abala o até então centro de gravidade do diálogo, a sua pintura atual; conferindo sentido, recentra-o, não tanto no trabalho propriamente dito, mas no produto desse trabalho, não tanto como resultante de um conjunto de procedimentos concretos, mas mais no produto qua produto, isto é, como obra, abrindo a possibilidade da equivalência (Boltanski \& Thévenot, 1991). Como correlato, temos que Leopoldo adquire o estatuto de pintor, qualidade em função da qual, como adiante se esclarecerá, pretende ser reconhecido, dando lugar a mais um modo da situação pulsar.

\section{...desdobramentos temporais em que o outro surge ao reconhecer as suas qualidades como pintor}

Nesse sentido, retenha-se apenas o rasgado sorriso estampado no rosto de Leopoldo no momento em que se viu interpelado. O visível agrado com que interrompeu o trabalho que estava a realizar, a ulterior diligência e solicitude que demonstra ao longo do diálogo, vincado na iniciativa de (se) mostrar sem ser por resposta a um 
pedido explícito, parecem indicar que Leopoldo viu na interpelação da funcionária uma oportunidade de ter a sua pintura apreciada, valorizada e assim reconhecida. Pela temporalidade inerente a esta demanda pelo reconhecimento, a experiência pictórica de Leopoldo é acomodada no diálogo. Isto porque esta temporalidade é, por definição, interativa, sempre clamando por um outro capaz de consideração. Ser reconhecido, na aceção que lhe damos, é ser considerado, não unicamente ao nível mais elementar do reconhecimento primário da humanidade comum, que ao mesmo tempo nos dá o outro na sua irredutível estranheza, mas também não exclusivamente do reconhecimento ao nível das qualificações e desempenhos, já posicionado. A temporalidade do reconhecimento obriga Leopoldo a arriscar-se no sempre indeterminado julgamento do outro, no caso o julgamento que a monitora e a funcionária tecem da sua pintura, engrandecendo-o ou diminuindo-o enquanto pintor, mas acopla identicamente uma dimensão em que é a sua humanidade, enquanto semelhante, mas singular e único que está em jogo. É por isso que no reconhecimento sempre se descobre implícita uma carga moral, que garante a passagem do singular ao geral, e vice-versa, e sem a qual não há reconhecimento, se por este entendermos justamente o resultado dessa passagem. Acontece que o reconhecimento nunca está garantido de uma vez para sempre. Tal não deve ser imputado a determinações psicológicas, sendo antes uma impossibilidade inscrita no coração do próprio reconhecimento graças ao cariz sequencial da ação: até ao momento da morte pode dar-se um evento que mude, de um só relance e retrospetivamente, toda o curso da vida. É do futuro, ou da sua impossibilidade de se fechar, que vem o reconhecimento.

Estamos, pois, perante uma temporalidade cujo nervo é o diferimento sobre o qual não pode deixar de se arrimar o movimento de se abandonar ao outro, assim como de deixar o outro vir a si. O diferir difere, logo o reconhecimento granjeado está sempre por terminar. Note-se quão heurístico se revela a monitorização destes pequenos deslocamentos da situação (que por vezes, inclusive, parece conduzir para fora da situação pertinente ao objeto de estudo, a criação artística), atenção pela qual pensamos ter recuperado algo essencial para compreender sociologicamente o ato de pintar e a pintura: ela destina-se sempre a outro, mesmo que, e sobretudo se, esse outro estiver em falta, indeterminado. Falta, paradoxalmente, que se dá a sentir precisamente no momento em que o outro já está sendo chamado, isto é, quando o reconhecimento já começou a arregimentar convenções qualificadoras. O outro e a falta acham-se sempre atrasados relativamente um ao outro.

Curioso será notar como a partir da banal pergunta de como está a correr o trabaIho, aplicada à atividade presente, se desdobram, desenvolvendo-se juntamente, formando uma duração situacional consistente, várias temporalidades diferentes: a 
de um futuro sempre por vir, ligado ao reconhecimento, como vimos, mas também a de um passado, materialmente contido no objeto-tela-antiga, portador de um outro espaço-tempo, e chegado até ao diálogo sob a forma de continuidade e permanência, resultante da maneira como Leopoldo o captura numa malha corporal, gestual e verbal. Mais uma vez, os objetos temporalizam. Somente se apanhados nesta malha que lhes dá oportunidade de enrugar a situação, é certo, mas não apenas por isso: a tela terminada há duas semanas, pelo mero facto de estar concluída, detém a força centrípeta dos objetos fechados, remetendo para o contexto em que foi produzida e assim delimitando e cravando um ponto no tempo. Pontuar é temporalizar. Além disso, paradoxalmente, a própria pintura, no seu conteúdo, mesmo que abstrato, exerce uma força no sentido contrário, centrífuga, descontextualizante: a pintura, o pintado, (per)dura para lá do seu contexto de produção, transcende as condições subjacentes à sua emergência, assim oferecendo ao mesmo tempo, por um lado, a dimensão da continuidade (enquanto objeto que permanece e resiste fechado), da pontuação temporal de que depende a cronologia, por outro, enquanto evento, oferecendo o instante enquanto momento vazio, irredutivel a um ponto, já e sempre cindido num passado e num futuro (Quéré, 2013).

\section{...pela experiência criativa, a interpelação de si no resultado do seu trabalho}

Por fim, as duas sequências de atividade, inicialmente distintas e separadas, depois juntas e imbricadas, voltam a desligar-se. A monitora e a funcionária afastam-se do local de trabalho de Leopoldo, que redireciona o foco de atenção para a pintura e retoma a sua atividade. O que resulta interessante é notar a reversibilidade desta sequência. Reversibilidade, não no sentido de regressar a um momento do passado tal-qual ele foi vivido e como se nada do que se seguiu tivesse ocorrido, o que é evidentemente impossível, mas no sentido de a interrupção da pintura imposta pela conversa não ter ameaçado a sua continuação após o interregno. Com efeito, Leopoldo recupera com aparente facilidade, denotada na ausência de qualquer manifestação (verbal, gestual ou facial) sintomática de perda de referência, a atividade no ponto em que a havia deixado aquando da interpelação da funcionária. Alegar a estrita diferença das duas sequências como condição desta retoma é insuficiente, descurando o fundamental, ou seja, a maneira como essa diferença se toca e afasta sem ser anulada. Tendo em conta o dito sobre a temporalidade da demanda do reconhecimento, da sua forma de se desenvolver em direção a um futuro que sempre se encontra em processo de determinar, podemos identificar a operação de congratulação que a monitora e a funcionária dirigem ao trabalho de Leopoldo, como sendo a ocasião em que o reconhecimento é colocado à prova, sendo superada e permitindo que o desenlace das duas sequências se proporcione serenamente, 
sem o assalto de nenhuma perturbação ou dificuldade eventualmente geradores de autoquestionamento.

A premência do fenómeno da retoma do trabalho acentua-se, porém: se Leopoldo nos diz demorar cerca de duas ou três horas a terminar cada tela, se a sessão nunca ultrapassa a duração de duas horas, então dificilmente uma tela é iniciada e concluída numa só sessão, o que significa que a pintura de uma mesma tela se transporta de uma sessão para outra, separadas no mínimo (conquanto Leopoldo não falte) por uma semana.

\begin{abstract}
Nesta sessão, Leopoldo propõe-se a dar seguimento à tela iniciada quinze dias antes, a 22 de maio. Pede ajuda com as tintas à monitora, para começar: onde estão os tubos de tinta? Como colocar a tinta na paleta? Que quantidade? E o diluente, onde se encontra? São todas questões em que, ainda antes de começar a pintar, Leopoldo requer o auxílio orientador da monitora, preferindo esperar (por vezes alguns minutos, quando a monitora se encontra a prestar apoio a outros residentes presentes na sessão) a resolver por sua iniciativa, logo também por sua conta e risco, estas questões logísticas/práticas. Em tendo estas questões resolvidas, inicia a continuação da tela. Pergunto-Ihe se Ihe é fácil ou se tem dificuldade em continuar o trabalho passado duas semanas. Ele responde que não, que "não the custa nada", parecendo-me, embora sem certeza, que a própria questão Ihe apareceu, de certo modo, desprovida de sentido (DC, 5 Jun. 2020).
\end{abstract}

Leopoldo, porque faltou a uma sessão, é obrigado a dar continuidade a um trabalho iniciado duas semanas antes. Nota-se novamente a pletora de dúvidas de natureza prática a que Leopoldo dá voz antes de iniciar a pintura, mas desta feita a perplexidade do observador aumenta na medida em que o trabalho já está iniciado, pelo que seria de supor que já tivesse uma ideia mais aproximada daquilo que consideraria necessitar. Mais uma vez, é pela dúvida que Leopoldo se instala na sequência de atividade pictórica, na situação que lhe é apropriada, nos ritmos pulsados pelas suas temporalidades. Já não, como então, pelo confronto com a tela-em-branco, mas talvez, e propomo-lo como mera hipótese, pelo confronto com uma tela lacunar. Não nos podemos deixar de questionar acerca da (in)completude da tela e respetiva finalização da pintura.

Durante a pintura, Leopoldo, vendo que eu permaneço sentado junto dele, inicia ele próprio a conversa comigo, sem com isso deixar de prosseguir o seu trabalho. Neste diálogo, refere-me várias coisas: sublinha a dificuldade de pintar abstrato, confidencia-me que não consegue pintar uma tela há dois meses (venho-me a aperceber que este "não conseguir" significa, não o ato em si de 
pintar, mas o facto de a levar até ao fim e gostar do resultado), diz que gostaria muito de acabar a tela que está a pintar naquele momento, mas que sabe que já não terá tempo suficiente e que, assim sendo, só poderá continuar passado uma semana (DC, 22 Maio 2020).

...no descompasso dos tempos:

pouco importa a lacuna da falta;

a insatisfação está no ensejo de pintar até ficar no ponto

O caráter lacunar da tela incompleta é, antes de tudo mais, sentido, como tal, Ionge de ser neutro, ele já se encontra sempre revestido de uma carga afetiva, ligada sobretudo à falta. Para que possa atuar efetivamente na sequência da ação, esta sensação de falta precisa de perdurar, isto é, de adquirir uma forma que lhe garanta consistência e solidez bastante, as quais apenas por intermédio da determinação de um conteúdo se fazem possíveis (noutros termos, juntando uma referência intencionada à carga intensionada). É por isso que à sensação de falta se deve juntar uma sensação do que falta, sem o que a primeira seria inoperante. Ora, acontece que, como se viu, Leopoldo não tem à partida uma chegada aonde a sua pintura deva desembocar, premissa que obstaculiza uma completa determinação do conteúdo em falta. Assim, compreende-se por que é o término da tela (logo, todos os seus estados intermédios, em processo de se fazer) uma questão que tem tanto de central como de problemática. Sem finalidade predefinida, ou tratando-se, quiçá, de uma finalidade sem fim, como diria Kant, já que, na verdade, a falta só se faz sentir quando referenciada ao completo, somos conduzidos a conceber algo como uma intencionalidade a-teleológica (Joas, 1996). Há qualquer coisa, brumosa e vaga, que atua às arrecuas e que não pode ser plenamente determinada a não ser pelo próprio ato de pintar, já que é justamente este que lhe vai dando uma forma concreta à medida que pincela. O que quer dizer que é do mesmo passo que a finalidade sem fim adquire, a cada vez, forma, e que esse indeterminável é alojado no seio da pincelada, o que precisamente impede que esta seja determinável em função de uma qualquer meta preestabelecida. Também por isso se possa talvez ousar dizer que estamos perante a forma no momento mesmo em que se esboroa e dilui no e pelo ato que lhe dá existência.

Esta é uma temporalidade do anseio, daquilo que se espera que chegue sem saber ao certo o que é nem se vai efetivamente chegar. Realmente, Leopoldo não sabe se a tela vai chegar a bom termo. Ultimamente, por exemplo, não tem conseguido consumar nenhum trabalho. O trabalho finda onde a sensação de falta, na sua dupla valência de intencionalidade e intensidade, é saciada. A certa altura, com maior subitaneidade ou progressividade, percebe-se que o trabalho terminou. Veremos 
que este momento não tem necessariamente que coincidir com a efetiva cessação do ato de pincelar, o que muito nos dirá acerca desta temporalidade. Encontramo-nos, enfim, em condições de arriscar uma leitura da possibilidade de retomar com aparente facilidade o trabalho iniciado há duas semanas. A tela lacunar, incompleta, despoleta uma sensação de falta, presente durante todo o tempo e que em torno dela trabalha, o que significa que é exatamente o anseio por esse fim, sempre mudo, que pontua o término da sessão em que iniciou a pintura sem a ter acabado, lançando-o num horizonte de espera que cobre o arco que vai de uma sessão a outra, doando-Ihe uma linha de continuidade. Duas semanas depois, Leopoldo, deparando-se com a sua tela, lacunar, vê-se enredado na sensação de falta, desposando aquela linha e, assim, vendo no início da nova sessão a oportunidade de retomar os trabalhos no ponto em que haviam sido deixados. Por isso é que a questão do pesquisador lhe pareceu desprovida de sentido, não obstante ter respondido, mas precisamente por causa dessa resposta: o "não custar nada" retomar a pintura não pertence tanto, como poderia fazer supor à primeira vista, a uma gramática da facilidade e do relaxamento (a linha de continuidade, aqui, não se estriba no hábito, na familiaridade, mas na espera ansiosa) quanto a uma urgência que se lhe é imposta sob a figura de oportunidade evidente, evidência que esvazia de sentido a questão do pesquisador.

Este caráter de urgência na pintura de Leopoldo é notório no ritmo a que pinta:

Leopoldo está preocupado com o tempo que (não) tem para acabar o seu trabalho ainda hoje. Caso contrário, terá que aguardar uma semana até haver novamente sessão de pintura. Leopoldo quer acabar rapidamente, mas teme não ter tempo. Transmite-o à monitora, que o tranquiliza, dizendo-Ihe que tem até às 16 horas para pintar. [...]. A dado momento, a hora de encerramento da sessão aproxima-se e a monitora comunica aos residentes que devem começar a arrumar os materiais, a limpar as mesas e a ir saindo com calma. Leopoldo revela-se tenso, a sua face contrai-se, mas resoluto, veloz e ágil nos movimentos que a pintura lhe solicita: molhar o pincel na tinta, aplicar a tinta na tela por intermédio do pincel, lavar, quando é necessário mudar de cor, o pincel com diluente, por vezes ir até ao lavatório, situado a aproximadamente cinco metros do local em que se encontra a pintar, e que percorre literalmente em passo de corrida, para lá e para cá, para molhar o pincel com água e posteriormente secá-lo com papéis. Quando ouve a monitora, murmura algo para si que eu, embora junto dele, não consigo compreender. Continua a pintar, quase sofregamente, garantindo à monitora, de viva voz, que está prestes a terminar. Olha para o relógio de pulso com frequência. Tudo isto enquanto pinta. Ainda assim, não se inibe de ser criterioso: apesar da superior morosidade que a troca de cor comporta, ele fá-lo sempre 
que entende necessário. Finalmente, diz que acabou, em voz alta, embora continue a pincelar a tela por mais uns breves minutos, talvez dois ou três (DC, 5 Jun. 2020).

Como é que Leopoldo, que se mostra incapaz de organizar devidamente os seus materiais antes de iniciar o trabalho, assim que o começa adquire a capacidade e destreza de os utilizar? E, o que é mais curioso, não apenas de os utilizar, mas de os manusear numa cadência a tal ponto veloz, frenética até, que dificilmente pode ser associado ao tempo sereno que costuma pontuar nos ambientes em que os utensílios consistem, à força do hábito, numa extensão do corpo. É, no mínimo, paradoxal que ao aumento de dificuldade técnica no uso dos instrumentos de trabalho atrelada ao aumento de velocidade não corresponda uma diminuição das capacidades de manuseio de Leopoldo, mas justamente o contrário. Não menos paradoxal é o facto de ser no momento em que Leopoldo passa a conseguir fazer um uso pleno dos materiais de pintura que, longe de se entrar num tempo calmo, como seria de esperar, vê-se antes emergir uma temporalidade turbilhonante, espiralada num movimento ascendente, progressivamente mais veloz que, em vez de providenciar segurança e previsibilidade, desencadeia o frenesim. Isto sem embargo dos esforços da monitora para o tranquilizar a respeito das horas. A seguinte entrada diarística, encadeada com a anterior, permitir-nos-á desenvolver esta e outras leituras:

[Depois de uma fase final de sessão semelhante à anterior, numa corrida contra o tempo], Leopoldo, já muito pressionado pela monitora relativamente ao fim da sessão, diz que a tela está concluída, ainda antes de efetivamente a concluir. Até concluí-la efetivamente, diz à monitora: "entreguei o meu máximo, doutora. Deu muito trabalho. Mesmo que não fique bonito, ficou a ideia". Assim que termina realmente a tela, isto é, de pintar, Leopoldo pergunta como deve fazer para lavar a paleta e o restante material, mostrando-se, se bem que descomprimido, desnorteado, sem saber o que fazer, perdido. Acabando a tela, dá a sensação de querer libertar-se o mais rapidamente possível do atelier (DC, 12 Jun. 2020).

Se, num primeiro momento, a monitora procura serenar Leopoldo, mas é também este que por si próprio se consegue alhear da passagem do tempo, com o avançar da hora a monitora age falando, proclamando o fim dos trabalhos e o início do processo de saída da sala, impregnando a sessão de uma atmosfera crepuscular, sensação de entardecer, declínio, queda após o auge, de onde a possibilidade do atraso. As duas descrições transatas parecem atestá-lo. Não tanto, talvez, pela velocidade imprimida, mas por um gesto particular: o olhar para o relógio. Este olhar, entre duas pinceladas, edifica uma ponte entre a pintura e a temporalidade institucional da sessão. O relógio, medida-padrão do tempo, fixa esta última e torna-a o eixo em 
função do qual as restantes temporalidades em jogo se medem. A pintura sai da "sua" temporalidade, coloca-se à medida das horas, sabe que the restam poucos minutos, atrasa-se.

...daquilo que está instituído transgredindo-o pelo instituinte:

da extrema sagacidade nos usos dos tempos ao seu imprevisível desnorte

Assomam, portanto, duas linhas de reflexão complementares acerca da aceleração que se produz na pintura de Leopoldo. Uma delas é esta última, que vê na temporalidade institucional, configurada por um conjunto de elementos inescapáveis - relógio, autoridade da monitora para decretar o encerramento da atividade, preestabelecimento do horário, etc. -, um acelerador externo das restantes temporalidades, sendo que se apresenta às outras temporalidades como sua medida-padrão. O momento de descompressão que segue imediatamente ao término da tela alude justamente ao facto de uma temporalidade se libertar da pressão da outra, aliviando-se. Prova disso mesmo é o facto de Leopoldo, mal acaba o trabalho, começar a falar dele no particípio passado, como se a tela pudesse cair para um tempo que já passou por se ter libertado de um enlaçamento temporal que a asfixiava.

Mas a descompressão parece provir igualmente de outras paragens, abrindo para uma outra linha de reflexão, não menos crucial, que segue o rastilho interno que acende e acelera a sua pintura, o qual é tão mais importante quando se observa que o aumento de velocidade não implica uma diminuição do critério que criva as suas opções pictóricas. Como argumentamos, enquanto a tela está por terminar ela apresenta-se a Leopoldo na qualidade de falha, gerando a espera ansiosa pela oportunidade apropriada de a colmatar. Vimos também que esta espera é a-teleológica, espera da espera, sem finalidade determinada, pelo que é a própria falha, enquanto urgência evidente, a magnetizar, ritmar, acelerar o ato de pintar, para aí adquirir e perder os seus contornos, renovando-se a cada pincelada. Neste sentido, a descompressão é também ela o alívio interno provocado pela colmatação da falha, pela sua completude, isto é, a consumação inerente ao caráter sequencial da ação (Dewey, 2008). Só desta maneira, isto é, tendo em mente o modo como a falha atua às arrecuas, se torna inteligível o facto de Leopoldo já se encontrar em descompressão, falando descontraidamente do seu trabalho à monitora, sem efetivamente ter parado de pincelar.

Ambas as linhas se acham juntas nas situações reportadas. Na verdade, só há atraso na espera, como só há espera na potencialidade do atraso. Formam um par indissociável, mas matizado situacionalmente. Veja-se como Leopoldo concilia em seu benefício estas duas linhas temporais. 
A dada altura, assinala verbalmente a conclusão da tela. Todavia, continua a pintar. Isto acontece em ambas as situações relatadas. Mais um paradoxo que não deve ser encarado como falsidade, imprecisão, lapso, ou acessório, mas antes, em primeiro lugar, como a semente a partir da qual ambas as temporalidades referidas se dão a ver, e em segundo lugar, como operação atuante na situação e na sequência da ação. Projetando-se numa fase da ação posterior à atual, presentificando-a fora do seu lugar, o que Leopoldo fundamentalmente faz é antecipar-se à ação. Talvez que seja a própria ação a ser ela mesma antecipada, já que, sem obstar à dissonância entre a sua proclamação e a sua ação física, só é possível a Leopoldo lançar-se desta maneira para a consumação da sequência da ação se estiver seguro dos próximos passos. Nesse sentido, é realmente a própria sequência que se antecipa, na medida em que o seu fim contamina a ação presente com um conteúdo, agora sim, já determinado. Não fosse assim e a frase de Leopoldo seria uma aposta cega que o colocaria em risco, sobretudo no contexto de pressão que se descreveu, e o impediria de falar relaxadamente com a monitora no lapso que vai da proclamação do término ao término físico.

O que acontece com esta antecipação? Decretando-a, Leopoldo fecha a sequência da ação antecipadamente. Porque se desvincula (deixa de haver com que se vincular), modificando o seu registo emocional, a diretiva pronunciada pela monitora de terminar a atividade perde o seu alvo, ecoa no vazio, já que a sequência da ação de Leopoldo refluiu. Claro que ele se encontra materialmente ali, pintando, mas modalizou a sua presença a ponto de se projetar numa outra sequência em que a pintura já faz parte do passado. Escudando-se em este estar-mas-não-estar (Piette, 2013), retira o tapete à diretiva de concluir e sair, desinvestindo a sua eficácia e desarmando a monitora. Desta maneira, mais do que propriamente ganhar tempo, aquilo que Leopoldo consegue é insuflar a temporalidade institucional, inserir no seu âmago uma bolsa de ar no qual se pode proteger da injunção de acabar o trabaIho e do imperativo de sair da sala, onde adquire uma folga para dar lugar proeminente a outras temporalidades. Fixando a monitora, pela frase que profere, numa ação que já acabou, ele preocupa-se em realizá-la para efetivamente terminá-la. Interessante é notar como a assimetria das relações interativas treme, mesmo que não ostensivamente, em função destas micro-operações que aplicam novas determinações à situação, fazendo o seu quadro deslizar.

Não podemos deixar de notar o que está para lá da descompressão. Leopoldo termina a sua pintura, outras tarefas se Ihe impõem, do foro prático e logístico, digamos, antes de sair da sala. O que é facto é que se já tínhamos sublinhado a dificuldade de Leopoldo no relacionamento com os materiais adstritos à pintura fora do ato de pintar em sentido estrito, no caso assumindo a figura da dúvida, da 
hesitação no começo da pintura, agora essa mesma dificuldade surge no final da sequência. Terminada a tela, parece ser tomado por um desnorte que o torna claramente deslocado. De repente, o atelier torna-se-lhe estrangeiro, sabe que deve lavar os materiais, mas não como o deve fazer, procura desembaraçar-se o mais rapidamente da sua bata e luvas, ambas descartáveis, os olhos vagam perdidos, ao mesmo tempo muito abertos, denotando alguma surpresa. A estranheza com que a mudança ocorreu, pela sua repentinidade, pelo facto de Leopoldo pintar há cerca de três anos, mas também pela radicalidade da alteração do seu estado, podem fazer supor algum afazer agendado para instantes depois. Não sabemos se assim é. Mas mesmo sendo esse o caso, seria de supor, sim, um conjunto de diligências para abreviar o processo de saída da sala, que poderiam passar putativamente por algum atropelo à civilidade convencional, mas não justifica a desorientação aguda que apontamos. Este episódio merece ser considerado na pesquisa que se encontra em curso, mas à data do presente texto ele parece mostrar um processo de perda de controlo da situação, onde Leopoldo se revela incapaz de encontrar os seus traços de significância, de entrar no ritmo adequado (de voltar a comprimir?), vendo-se desfasado, assíncrono. Não encontrando o pulso da temporalidade, Leopoldo é remetido para fora do tempo, ficando assustado e até, num certo sentido, paralisado.

A situação vai-se formando ao longo de linhas que a atravessam e transformam. Ora, estas transformações nem sempre são acomodáveis na situação atual, conduzindo, por vezes, à sua fratura, a qual é, não raras vezes, necessária e até desejável. Comummente, cada situação detém modos próprios, mais ou menos codificados, de se the aceder e sair, pelo que os atores, seres que participam em várias situações, mas também em várias sequências de ação, mesmo no seio da mesma situação, devem estar munidos das gramáticas apropriadas para transitar entre elas. No caso apresentado, mesmo não tendo ocorrido nenhum evento abrupto, a situação parece ter sido cindida, não conseguindo Leopoldo ajustar a sua conduta adequadamente de forma a sair daquela sem percalços de maior. Estas dificuldades, no entanto, não são a regra, pelo menos no caso de Leopoldo. Leia-se, para rematar, a seguinte entrada do diário, onde fica patente a astúcia situacional do residente do Casp em manejar duas sequências de ação diversas:

A monitora, passando junto de Leopoldo, e tendo este já praticamente terminado o seu trabalho, pergunta-lhe "de que modo o seu trabalho tem a ver com a Covid-19?" [durante a pandemia a instituição tem promovido a realização de trabalhos tendo a mesma por mote, mesmo que indiretamente]. Responde-Ihe Leopoldo que "não pintou com nenhum intuito". A partir daí, a monitora começa a interpretar a tela em função da pandemia: nalguns traços 
sobressai a forma de gaivotas, de onde a alusão à liberdade, a qual se encontra limitada pelas restrições impostas. Leopoldo, ouvindo atentamente, concorda com a interpretação e diz que "não tinha pensado nisso". De facto, nem antes nem depois da explicitação da monitora o Leopoldo adiantou qualquer tipo de explicação, interpretação, sequer comentário do conteúdo da tela, muito menos ligando-o à Covid-19 (DC, 22 Maio 2020).

Mais uma vez, Leopoldo vinca explicitamente a ideia de que "não pinta com nenhum intuito", pelo que o seu trabalho não é passível de ter por base um motivo predefinido. É por isso que ele "nem pensou" na relação que a sua tela poderia ter com a pandemia de Covid-19. Até aqui, nada de novo. Entretanto, a monitora sugere, verbalizando, uma leitura do trabalho corrente em que encadeia inferencialmente símbolos evocadores, levando o mesmo a desaguar naquilo que deveria ter sido o seu mote. O que está em causa é um processo inferencial que opera uma reversão que converte a interpretação da tela no seu mote, alquimia que não encontra suporte naquilo que Leopoldo nos diz do seu trabalho (a ausência de ponto de partida etc.). Como reage Leopoldo? Primeiro, volta a atenção para a interlocutora, escuta-a, concede lugar no seu trabalho à interpretação alheia; depois, dizendo que "não tinha pensado nisso", lança mão de uma modalidade cordial pela qual consegue aceitar a sugestão, que afronta ostensivamente a sua afirmação de ausência de intuito, sem com isso criar conflito, sequer tensão.

A civilidade do "não tinha pensado nisso" é irresistível pela duplicidade que institui: ele é simultaneamente um "não tinha pensado nisso, não importa" e um "de facto, não tinha pensado nisso". Esta duplicidade não se atém simplesmente ao conteúdo das palavras, mas à envolvente em que Leopoldo as profere: voltando a atenção para a monitora, confere importância e centralidade ao seu discurso, valorizando-o e integrando-o na sequência pictórica, mas o modo como se escusa a complementá-lo é lapidar, no sentido de ser conciso, mas igualmente sepulcral. Nesta duplicidade, o residente consegue aceitar a leitura da monitora, sem discordar, podendo inclusivamente até dar-se ao luxo de concordar, legitimando-a, mas outorga-Ihe nesse mesmo passo o estatuto de superfluidade, relativizando a sua concordância. Estamos, pois, perante uma operação de amortecimento do significado (Piette, 2013), através da qual Leopoldo está e não está presente em cada uma das sequências de ação que aqui se encontram e cujo confronto poderia, de resto, conduzir à supressão do seu trabalho. Ele encontra um abrigo, plataforma de descanso, no qual está distante na presença. O "sim, pode ser isso" implícito no "não tinha pensado nisso" amortece na medida que torna irrelevante o conteúdo da interpretação, podendo ele, a partir daí, concordar com indiferença, sem aderir. É por isso que, logo depois, reinicia a sua pintura sem obstáculos. 


\section{Finalizar para abrir outros feixes temporais a explorar no futuro}

Com o rastreio da multiplicidade de temporalidades no atelier de pintura do Casp pensamos ter podido mostrar que a noção de situação, conforme cunhada nas sociologias pragmatistas, não implica, antes pelo contrário, que nos limitemos às condições imediatas da atividade prática (Dodier \& Motlow, 1995). Ela não se restringe a um aqui-e-agora. Se ela, equivocamente, assim tem sido compreendida, deve-o ao facto de a sociologia ter reduzido a variedade de temporalidades a duas grandes tendências: uma que privilegia a consolidação do futuro, enfatizando a centralidade do esquema estratégico-racional-individual, outra voltada para a cristalização do passado, de cariz mais disposicional (Breviglieri \& Stavo-Debauge, 1999). Talvez possamos ainda acrescentar outra, segundo a qual, de pendor mais historicista, a temporalidade se conduz segundo uma lógica evolutiva. Primando ambas pela consolidação de uma só temporalidade a que conferem primazia, ou, no caso desta última, uniformizando as várias temporalidades, tornando-as sucessivas, é natural que vejam na situação um mero presente vazio de significância.

Da nossa perspetiva, a situação só o é justamente à força de não-univocidade nem determinabilidade do tempo, que a abre a um horizonte de futuro, mas também a uma continuidade do passado, e cuja experiência fenomenológica é variável. Como vimos - o que aliás é crucial para pensar a vulnerabilidade -, nem sempre é possível fazer situação, por diversas razões. Aí, os atores tornam-se deslocados e a ação é inibida, paralisada. É por isso que é imprescindível resistir a subsumir a multiplicidade de temporalidades a um recorte espácio-temporal empírico que rasuraria a variedade e perderia as modalidades específicas em que as mesmas se enlaçam e compõem, para nos lançarmos no acompanhamento dos ajustes reais feitos pelos atores no curso da ação e através dos quais os vários regimes de ação se articulam e derrapam uns para os outros.

Este presentismo metodológico não anula o facto de, como disse George H. Mead (1932), toda a situação ser simultaneamente uma história e uma profecia. O esforço etnográfico realizado, conforme aqui foi apresentado, procurando reunir alguns referenciais das tradições pragmatista e fenomenológica, atendeu às dimensões existenciais, práticas, afetivas, climático-atmosféricas, corporais, objetais e discursivas da situação na esperança de cumprir o desígnio de dar ao leitor a ideia de como as temporalizações são feitas in situ (Cefai, 2010), linhas a partir das quais os atores se sincronizam e dessincronizam no curso da ação, modulando o seu engajamento com o mundo, adquirindo e perdendo o controlo das situações, ao fim e ao cabo, pintando. Pensamos, desta forma, ter podido enriquecer a conceção reticular das 
situações, onde cada ator, seja humano ou não-humano, pertence às mesmas na medida da sua participação ativa, do seu caráter atuante, da sua presença, mesmo que à distância. Mais do que conectar e dar forma a uma rede, as linhas que ligam e seguram a situação são experienciadas segundo modos presenciais diversos (Ingold, 2011), isto é, segundo capturas (Chateauraynaud, 2017) que vinculam afeções, perceções, ações, cognições em geometrias variáveis. Como vimos, a situação só o é na medida em que coloca o ator num eixo sempre misto, entre a ausência e a presença, a passividade e a atividade, mas, salvo raras exceções, nunca completamente um ou outro. O pragmatismo sociológico conforme o pretendemos desenvolver permite, na senda de outros trabalhos (Breviglieri, 2016; Stavo-Debauge, 2012), dar conta dos momentos em que os atores se encontram paralisados e onde a ação é inibida, mas igualmente percorrer toda a gama de modos de estar e engajar-se consigo, com os outros e com o mundo. É contra esta rasura das modulações temporais e uniformização do modus presencial que leva Nick Lee e Steve Brown (1994) a alertar contra o risco da actor-network theory (ANT) se tornar uma formulação metalinguística sem espaço para o estranho, para o irredutivelmente outro (Stavo-Debauge, 2015), mas também para as transformações, elementos fundamentais para pensar as modalidades de habitar o espaço.

A natureza paradoxal de boa parte do que foi afirmado no texto poderá soar a artifício linguístico, subterfúgio retórico mediante o qual apresentar as contradições como possíveis. Se assim for, simplesmente esclarecemos que o nosso ponto de vista é divergente: é a contradição que é produto da linguagem, sobretudo a logicista, mas não só, a qual despoja o paradoxo da sua riqueza, capturando-o segundo a fórmula ou-ou. O paradoxo é a mola do sentido, o disparo originário da fricção exercida entre duas sequências de ação irredutivelmente diferentes, embora comunicáveis e que se ligam debaixo de uma lógica $e$-e, mais não seja pela resistência bruta que impõem e sem a qual não há engajamento no mundo. É por isso que consideramos que a conduta de Leopoldo a que fomos assistindo não deve ser subsumida ao abrigo de um qualquer conceito que se proponha explicá-la a partir de determinações exteriores e/ou individuais. Veja-se que é ao mesmo tempo que Leopoldo lamenta não poder prosseguir a sua pintura de modo a terminá-la na sessão em causa e que diz que não Ihe custa retomar a pintura após interrupção; do mesmo modo que é ao mesmo tempo que ele não sabe o que fazer com os materiais antes e depois de iniciar a pintura e que durante a mesma os manuseia com uma agilidade veloz digna de registo. Tudo isto, é claro, depende do que queremos dizer com a expressão "ao mesmo tempo", o que só enfatiza a premência e necessidade de desposar com o olhar, mas com os restantes canais sensoriais fundamentais à pesquisa, as várias temporalidades em cena e o jogo dos seus cruzamentos para compreender o quando da situação da criação pictórica. A situação amarrota-se, adquire, de um só 
jato, sentido e valor, na medida em que se temporaliza, isto é, modalizando o seu aparecimento, durando. Foi nessas águas que navegámos em compassos e descompassos, levando a sério os laços de Leopoldo com os seus ambientes atmosféricos, não deixando de atender às minudências das ações observadas.

\section{Referências}

BIDET, Alexandra. Le corps, le rythme et l'esthétique sociale chez André Leroi-Gourhan. Techniques \& Culture, n. 48-49, p. 15-38, 2007.

BOLTANSKI, LUC; THÉVENOT, Laurent. De la justification. Les économies de la grandeur. Paris: Éditions Gallimard, 1991.

BRAHY, Rachel. L'engagement en présence: I'atelier de théâtre-action comme support à une participation sociale et politique. Lien Sociale et Politiques, n. 71, p. 3149, 2014.

BREVIGLIERI, Marc. Pensar a dignidade sem falar a linguagem da capacidade de agir: uma discussão crítica sobre o pragmatismo sociológico e a teoria do reconhecimento de Axel Honneth. Terceiro Milénio: Revista Crítica de Sociologia e Política, v. 6, no. 1, pp. 11-34, 2016.

. L'espace habité que réclame l'assurance intime de pouvoir. Études Ricoeuriennes / Ricoeur Studies, v. 3, n. 1, p. 34-52, 2012.

BREVIGLIERI, Marc; STAVO-DEBAUGE, Joan. L'hypertrophie de l'œil. Pour une anthropologie du "passant singulier qui s'aventure à découvert". In: CEFAI, Daniel; SATURNO, Carole (Dirs.). Itinéraires d'un pragmatiste. Autour d'Isaac Joseph. Paris: Economica, 2007.

Le geste pragmatique de la sociologie française. Autour des travaux de Luc Boltanski et Laurent Thévenot. Antropolítica, n. 7,pp. 7-22, 1999.

CEFAI, Daniel. Provações corporais: uma etnografia fenomenológica entre moradores de rua de Paris. Lua Nova, n. 79, p. 71-110, 2010.

CHATEAURAYNAUD, Francis. A captura como experiência: investigações pragmáticas e teorias do poder. Revista Brasileira de Ciências Sociais, v. 32, n. 95, p. 1-21, 2017.

COLAPIETRO, Vincent. Time as experience/Experience as temporality: pragmatic and perfectionist reflections on extemporaneous creativity. European Journal of Pragmatism and American Philosophy, v. 5, n. 1, 2013. 
DEWEY, John. El arte como experiencia. Barcelona, Es: Paidós, 2008.

DODIER, Nicolas; MOTLOW, David. The conventional foundations of action. Elements of a sociological pragmatics. Réseaux, v. 3, n. 2, p. 145-166, 1995.

GIBSON, James. The ecological approach to visual perception. Mahwah, NJ: Lawrence Erlbaum Associates Inc, 1986.

GIL, José. Movimento total: o corpo e a dança. Lisboa: Relógio d’Água, 2001.

GOFFMAN, Erving. Ritual de interação. Ensaios sobre o comportamento face a face. Petrópolis, RJ: Vozes, 2011. Encounters. Indianapolis, IN: Bobbs-Merrill, 1961.

INGOLD, Tim. Against space: place, movement, knowledge. In: KIRBY, Peter (Ed.). Boundless worlds. An anthropological approach to movement, p. 29-43. Oxford, UK: Berghahn Books, 2011.

The perception of the environment: essays on livelihood, dwelling and skill. London: Routledge, 2000.

JOAS, Hans. The creativity of action. Cambridge, UK: Polity Press, 1996.

LAW, John. Objects and spaces. Theory, Culture \& Society, v. 19, n. 5-6, p. 91-105, 2002.

LEE, Nick; BROWN, Steve. Otherness and the actor network: the undiscovered continent. American Behavioral Scientist, v. 37, n. 6, p. 772-790, 1994.

MEAD, George Herbert. Mente, self e sociedade. São Paulo: Ideias \& Letras, 2010. . The philosophy of the present. Illinois, IL: Open Court, 1932.

MOL, Annemarie; LAW, John. Regions, networks and fluids: anaemia and social topology. Social Studies of Science, n. 24, p. 641-671, 1994.

OGIEN, Albert. Pragmatismes et sociologies. Revue Française de Sociologie, v. 55, n. 3, p.563-579, 2014.

PEIRCE, Charles Sanders. The essential Peirce: selected philosophical writings, v. II (1893-1913). Indiananapolis, IN: Indiana University, 1998.

PIETTE, Albert. Au coeur de l'activité, au plus près de la présence. Réseaux, n. 182, p. 57-88, 2013. 
QUÉRÉ, Louis. Les formes de l'événement. In: BALLARDINI, Elio; PEDERZOLI, Roberta; REBOUL-TOURÉ, Sandrine; TRÉGUER-FELTEN, Geneviève (Eds.). Mediazioni, n. 15, Special Issue: "Les facettes de l'événement: des formes aux signes", 2013.

QUÉRÉ, Louis, SCHOCH, Cynthia. The still-neglected situation? Réseaux. The French Journal of Communication, v. 6, n. 2, p. 223-253, 1998.

SCHATZKI, Theodore. Materiality and social life. Nature and Culture, v. 5, n. 2, p.123149, 2010.

STAVO-DEBAUGE, Joan. De "The Stranger" d'Alfred Schutz au cas "Agnès" d'Harold Garfinkel. Des théories sociales étrangeres à l'hospitalité et au pragmatisme? Sociologies [En ligne], Dossiers: "Pragmatisme et sciences sociales: explorations, enquêtes, expérimentations", Fev. 2015.

. Des "événements" difficiles à encaisser. Un pragmatisme pessimiste. In: CEFAI, Daniel; TERZI, Cédric (Dirs.). L'expérience des problèmes publics. Perspectives pragmatistes. Paris: Éditions de l’Ehess, 2012.

THÉVENOT, Laurent. "Ce qui engage: la sociologie des justifications, conventions et engagements, à la rencontre de la norme". La Revue des Droits de L'Homme, n. 16, 2019.

Pragmatic regimes governing the engagement with the world. In: KNORR-CETINA, Karin; SCHATZKI, Theodore; SAVIGNY, Eike von (Eds.). The practice turn in contemporary theory, p. 56-73. London: Routledge, 2001.

Rules and implement: investment in forms. Social Science Information, v. 23, n. 1, p.1-45, 1984. 